\title{
Respuesta al estrés quirúrgico: Gasto metabólico basal, cortisol y glucemia. Tratamiento perioperatorio
}

\author{
Ferro S. ${ }^{1}$, Mangiarotti E. ${ }^{1}$, Peroni D. ${ }^{1}$, Godoy SM. ${ }^{1}$, Tami MF. ${ }^{1}$, Martínez A. ${ }^{1}$, Pineda F. ${ }^{1}$, Salvatori F. ${ }^{1}$, Chávez \\ D. 1
}

1 Hospital Magdalena V de Martínez, Gral Pacheco, Argentina.

Introducción: El estrés quirúrgico desencadena en el paciente alteraciones secretorias del eje neurohipófiso-suprarrenal, con la consecuente liberación de cortisol.

Este, junto a otras hormonas endógenas (catecolaminas, prolactina, glucagón) es liberado al plasma en cuadros de ansiedad o estrés produciendo hiperglucemia, taquicardia, taquipnea, hipertensión arterial y malestar general.

La magnitud del estímulo estresor, el ayuno innecesariamente prolongado y/o un sueño liviano no reparador condicionan también aumentos en el Gasto Metabólico Basal (GMB).

En un alto porcentaje de pacientes la respuesta metabólica al estrés provoca el consumo de reservas (hormonas catabólicas que favorecen la proteólisis) y al mismo tiempo, la adaptación al ayuno se bloquea.

Todo esto conlleva a alteraciones hemodinámicas y del metabolismo que se manifestaran en la morbimortalidad perioperatoria.

El objetivo de este trabajo es medir concentraciones de cortisol, glucemia y nitrógeno urinario como indicadores de estrés y gasto metabólico en pacientes seleccionados que reciben premedicación ansiolítica, confort intraoperatorio y ayuno estricto de ocho horas.

Materiales y Métodos: Se seleccionan treinta pacientes de ambos sexos, ASA I - II, entre 20 y 60 años de edad, con indicación de cirugía electiva de mediana complejidad.

Se excluyen pacientes en tratamiento con depresores del SNC o con patología endócrina.

Se dividen al azar en dos grupos de quince pacientes:

Grupo A: Visita preanestésica; Alprazolam 0,02 mg/kg VO (al inicio del ayuno); Musicoterapia al ingreso a quirófano hasta el momento del despertar. Ayuno que NO supere las $8 \mathrm{~h}$.

Grupo B: Visita preanestésica con indicaciones habituales.

Ambos grupos recibirán anestesia general balanceada y se les realizan los siguientes controles:

Niveles de cortisol entre las $8 \mathrm{~h}$ y las $9 \mathrm{~h}$ de la mañana el día previo a la cirugía y en el mismo horario el día de la intervención.

Controles de glucemia al ingreso a quirófano.

Glucemia y nitrógeno urinario a las $24 \mathrm{~h}$ del postoperatorio.

Intraoperatorio, registros de: Tensión arterial, Frecuencia cardíaca, Requerimiento de estabilizadores de TA.

Postoperatorio, se evalúa: Sensaciones displacenteras; Requerimiento de analgésicos; Estabilidad emocional; Recuerdo del procedimiento; Condiciones de alta.

Resultados: A través de métodos farmacológicos (ansiolíticos) y no farmacológicos (empatía prequirúrgica, confort intraoperatorio) se logra: Disminución de liberación de cortisol y hormonas de estrés; Mayor estabilidad intraoperatoria; Menor proteólisis, mejor adaptación al ayuno y menor gasto energético basal; Estabilización normoglucémica en el postoperatorio.

Lo anteriormente dicho se ve reflejado en menor requerimiento de analgesia en las 24 h postoperatorias, disminución del tiempo de internación y recuerdo placentero del evento quirúrgico.

https://doi.org/10.25237/congresoclasa2019.88 